Check for updates

Cite this: RSC Adv., 2019, 9, 10966

\title{
High resolution tracking of macrophage cells in deep organs and lymphatics using fluorescent polymer dots $\uparrow$
}

\author{
Shiyi Tang, ${ }^{a}$ Yixiao Guo, ${ }^{a}$ Yidian Yang, ${ }^{\text {ab }}$ Yao Li, ${ }^{a}$ Yanhong Gao, ${ }^{c}$ Chunfu Zhang ${ }^{a}$ \\ and Liqin Xiong (iD *a
}

In vivo cell tracking can provide information on cell migration and accumulation in the organs. Here, both folate and amino modified polymer dots were synthesized and screened for in vitro and in vivo tracking of macrophage Ana-1 cells. Flow cytometry analysis demonstrated that prepared polymer dots showed cellular uptake of approximately $98 \%$ within a short incubation time of $2 \mathrm{~h}$, and these polymer dots maintained a cell labeling rate over $97 \%$ after $2 \mathrm{~d}$. Moreover, a CCK- 8 assay suggested that these polymer dots increased Ana1 cell viabilities up to $110 \%$ at concentrations from 5 to $50 \mu \mathrm{g} \mathrm{mL}$. Furthermore, the in vivo real time imaging of labelled Ana-1 cells in the alveolus of lung and lymph nodes were clearly detected by probebased confocal laser endomicroscopy ( $\mathrm{CCLE}$ ). This study demonstrates a unique approach using polymer dots for real-time high resolution tracking of macrophage cells in deep organs and the lymphatic system.

Received 5th February 2019

Accepted 3rd April 2019

DOI: 10.1039/c9ra00954j

rsc.li/rsc-advances

in cancer patients. However, limited penetration depth of optical wavelength photons and high autofluorescence from living tissues that significantly compromises imaging sensitivity and specificity. ${ }^{20-22}$ These issues can be tacked by using imaging probes that emit in the near-infrared (NIR) wavelength range. ${ }^{23-27}$ Semiconducting polymer dots, as an attractive fluorescent nanoprobe, have gained growing interest for their attractive optical properties, such as bright fluorescent intensity, long-time photostability, high emission rate, and low cytotoxicity. ${ }^{17,19,28-38}$ In addition, the colors of polymer dots can be widely regulated by modifying their structures. And NIR emission can be realized based on the fluorescence resonance energy transfer (FRET) effect. ${ }^{30}$ In this study, NIR775-doped poly [2-methoxy-5-(2-ethylhexyloxy)-1,4-phenylenevinylene] (MEHPPV) polymer $\operatorname{dots}^{39}$ were used as NIR fluorescence imaging probes for in vitro and in vivo cell tracking macrophage Ana-1 cells. In addition, by combining probe-based confocal laser endomicroscopy (pCLE), real-time imaging macrophage cell in deep organs and lymphatics were obtained.

\section{Experimental}

\section{Materials}

Polystyrene graft EO functionalized with carboxy (PS-PEG-COOH) and amino terminated poly(methyl methacrylate) (MMA- $\mathrm{NH}_{2} ; M_{\mathrm{n}}$ $=31000 \mathrm{~g} \mathrm{~mol}^{-1}$ ) were purchased from Polymer Source Inc. Folate Cap PE (PE-FA) was purchased from Avanti, Polar Lipids, Inc. Poly[2-methoxy-5-(2-ethylhexyloxy)-1,4-phenylenevinylene] (MEH-PPV; MW: 150 000-250 000 Da) was purchased from J\&K, Inc. Silicon 2,3-naphthalocyanine bis(trihexylsilyloxide) (NIR775) was purchased from Sigma Aldrich, Inc. Anti-F4/80 antibody 
[CI:A3-1] (ab6640) and Donkey Anti-Rat IgG H\&L (Alexa Fluor® 488) preadsorbed (ab150153) were purchased from Abcam Plc. Other chemicals were used without purification.

\section{Preparation of polymer dots}

The FA-MEH-PPV-COOH, MEH-PPV-COOH, FA-MEH-PPV-NH ${ }_{2}$ and $\mathrm{MEH}-\mathrm{PPV}-\mathrm{NH}_{2}$ polymer dots were prepared by the coprecipitation according to our previous study, ${ }^{39-43}$ with some modifications. In a typical procedure, a solution of $2 \mathrm{~mL}$ of THF containing $250 \mu \mathrm{g}$ MEH-PPV and $250 \mu \mathrm{g}$ PS-PEG-COOH or 250 $\mu \mathrm{g}$ MMA-NH $\mathrm{H}_{2}$ and $5 \mu \mathrm{g}$ NIR775 with/without $50 \mu \mathrm{g}$ PE-FA was mixed in stock. Then, the mixture was quickly dispersed into $10 \mathrm{~mL}$ of purified water under water ultrasound. Extra THF was evaporated at $45^{\circ} \mathrm{C}$ under the protection of nitrogen for $30 \mathrm{~min}$. Finally, the prepared polymer dots were passed through a 0.45 $\mu \mathrm{m}$ filter with a PVDF membrane.

\section{Characterization of polymer dots}

The particle size and zeta potential of the polymer dots were measured in aqueous solution using a Dynamic Light Scattering (DLS) instrument (Brookhaven 90 Plus Nanoparticle Size Analyzer). The absorption spectrum $(360-750 \mathrm{~nm})$ was obtained with a Shimadzu UV-2550 ultraviolet-visible spectrometer. The fluorescence spectrum (562-800 nm) was measured with an excitation wavelength at $537 \mathrm{~nm}$ with SpectraMax i3x (MOLECULAR DEVICES). pH was measured by FiveEasy Plus (METTLER TOLEDO). The fluorescence quantum yield (QY) of the polymer dots was measured with a UV-NIR absolute PL QY spectrometer (Hamamatsu, Japan) with $510 \mathrm{~nm}$ excitation for polymer dots from a xenon lamp. ${ }^{42}$ In the size and fluorescence stability test, polymer dots were dispersed in DMEM supplemented with $10 \%$ FBS at $37{ }^{\circ} \mathrm{C}$ for $96 \mathrm{~h}$.

\section{In vitro cell culture, cytotoxicity and cell imaging}

The Ana-1 cell line was obtained from the cell bank at the Chinese Academy of Sciences (Shanghai, China). QBC, GBC-SD, SGC-996 and RBE cell lines were kindly provided from Dr Fei Ma of Xinhua Hospital of Shanghai Jiao Tong University. The Ana-1, RBE and NCI-H292 cell lines were grown in RPMI 1640 medium. The QBC, SGC and GBC-SD cell lines were grown in DMEM. The media mentioned above were supplemented with 10\% FBS and $1 \%$ penicillium streptomycin. Cultures were maintained at $37{ }^{\circ} \mathrm{C}$ under a humidified atmosphere containing $5 \% \mathrm{CO}_{2}$.

The in vitro cytotoxicity test was measured using the CCK-8 assay in Ana-1, NCl-H292, QBC, SGC, GBC-SD and RBE cell lines. Cells growing in log phase were seeded onto a 96-well cellculture plate for approximately $5 \times 10^{3}$ cells per well and then incubated for $12 \mathrm{~h}$ at $37{ }^{\circ} \mathrm{C}$ under $5 \% \mathrm{CO}_{2}$. Then, corresponding dots were added at different concentrations (0, 5, 25, 50, and $100 \mu \mathrm{g} \mathrm{mL}^{-1}$ ), and $100 \mu \mathrm{L}$ per well DMEM/1640 was added to the negative control group and incubated for $24 \mathrm{~h}$.

Subsequently, $10 \mu \mathrm{L}$ of CCK-8 was added to each well of the 96well plate and incubated for an additional $2 \mathrm{~h}$ at $37{ }^{\circ} \mathrm{C}$ under $5 \%$ $\mathrm{CO}_{2}$. A Tecan microplate reader was used to measure the OD450 (A value) of each well. Cell viability $=$ (mean of absorbance value of treatment group/mean of absorbance value of control) $\times 100 \%$.
For cell imaging, $5 \times 10^{4}$ Ana-1 cells grown on 6-well cell culture plates were cultured in RPMI 1640 medium for $12 \mathrm{~h}$ and then incubated with polymer dots $(\sim 20 \mu \mathrm{g})$ at $37^{\circ} \mathrm{C}$ for $2 \mathrm{~h}$. After washing, the cells were imaged under a fluorescence microscope, LEICA DM I 3000B (Leica, Germany).

To analyze the specific protein markers F4/80 of macrophages, Ana-1 cells were investigated by immunofluorescence staining and laser confocal imaging. ${ }^{44}$ A total of $1 \times 10^{6}$ Ana- 1 cells grown on confocal dishes were cultured in RPMI 1640 medium. After incubating for $24 \mathrm{~h}$, the cells were fixed with $4 \%$ paraformaldehyde for $15 \mathrm{~min}$. After washing in PBS for $5 \mathrm{~min}$, the cells were permeabilized in $0.3 \%$ Triton for $15 \mathrm{~min}$. After washing three times, the cells were blocked with $10 \%$ serum for $30 \mathrm{~min}$ at room temperature. The Ana-1 cells were then incubated with the macrophage-specific protein F4/80 (1:300) for $24 \mathrm{~h}$ at $4{ }^{\circ} \mathrm{C}$. After washing with PBS, the secondary antibody ( $1: 300)$ was applied and incubated for $2 \mathrm{~h}$ at room temperature in the dark. After washing with PBS, the cells were stained with DAPI for $10 \mathrm{~min}$ at room temperature in the dark. Subsequently, the laser confocal imaging was analyzed.

For laser scanning confocal imaging, Ana-1 cells were incubated with polymer dots for $12 \mathrm{~h}$. After washing, the cells were immobilized by paraformaldehyde. Nuclei were stained with 4',6-diamidino-2-phenylindole (DAPI) staining solution at room temperature. Images revealing DAPI (excitation: $405 \mathrm{~nm}$, emission: 430-520 nm), MEH-PPV (excitation: $561 \mathrm{~nm}$, emission: 585-650 nm), NIR775 (excitation: $561 \mathrm{~nm}$, emission: 750-790 $\mathrm{nm}$ ) and F4/80 (excitation: $488 \mathrm{~nm}$, emission: 508-530 nm) fluorescence were captured using a laser scanning confocal microscope Leica TCS SP5 (Leica, Germany). The confocal images were analyzed using LAS AF Lite software.

\section{Flow cytometry assay}

Ana- 1 cells $\left(1 \times 10^{6}\right.$ cells $)$ were incubated with polymer dots $(\sim 20 \mu \mathrm{g})$ at $37^{\circ} \mathrm{C}$ for 2,6 , and $10 \mathrm{~h}$. After washing, the cells were resuspended in PBS and analyzed with a flow cytometer Accuri C6 (BD, USA) by counting $10^{4}$ events. The collected data were analyzed using BD Accuri C6 software. The fluorescence emission channel setting was $610 \pm 10 \mathrm{~nm}$.

\section{Biological distribution in balb/c mice}

Balb/c mice ( $25 \mathrm{~g}, n=12)$ were anesthetized with $200 \mu \mathrm{L}$ of pentobarbital sodium (1\%) by intraperitoneal injection. Then $50 \mu \mathrm{g}$ four typical MEH-PPV polymer dots were intravenously injected to the mice. After $2 \mathrm{~d}$, mice were euthanized by cervical dislocation. The lymph nodes (cervical, axillary, inguinal, popliteal, and medial iliac lymph nodes), major organs (heart, liver, spleen, lungs, and kidneys), interscapular brown adipose tissue (iBAT), ${ }^{42}$ muscle and bone were isolated. Ex vivo fluorescence imaging was performed with the IVIS Lumina XRMS Series III Imaging System by using a $520 \mathrm{~nm}$ excitation filter and a $790 \mathrm{~nm}$ emission filter (bin =8).

\section{Long-time cell labeling rate and fluorescence intensity}

Ana- 1 cells $\left(1 \times 10^{6}\right.$ cells $)$ were incubated with FA-MEH-PPV$\mathrm{NH}_{2}$ and FA-MEH-PPV-COOH polymer dots $(\sim 20 \mu \mathrm{g})$ at $37^{\circ} \mathrm{C}$ 
Table 1 The material ratio, size distribution, zeta potential and $\mathrm{pH}$ of polymer dots

\begin{tabular}{|c|c|c|c|c|c|c|c|c|}
\hline Sample & МEH-PPV ( $\mu g)$ & NIR775 $(\mu \mathrm{g})$ & PS-PEG-COOH $(\mu \mathrm{g})$ & MMA-NH ${ }_{2}(\mu g)$ & PE-FA $(\mu g)$ & Size (nm) & Zeta (mV) & $\mathrm{pH}$ \\
\hline FA-MEH-PPV-COOH & 250 & 5 & 250 & 0 & 50 & $50.38 \pm 5.43$ & $-37.0 \pm 0.9$ & 6.40 \\
\hline MEH-PPV-COOH & 100 & 3 & 100 & 0 & 0 & $47.93 \pm 3.60$ & $-34.2 \pm 1.6$ & 6.38 \\
\hline MEH-PPV-NH ${ }_{2}$ & 100 & 3 & 0 & 100 & 0 & $54.06 \pm 2.72$ & $-39.5 \pm 1.7$ & 6.60 \\
\hline
\end{tabular}

for $24 \mathrm{~h}(n=3)$, respectively. After washing with PBS, half of the cells were resuspended in PBS and analyzed with a flow cytometer Accuri C6 (BD, USA) by counting $10^{4}$ events. The collected data were analyzed using BD Accuri C6 software. The fluorescence emission channel setting was $610 \pm 10 \mathrm{~nm}$. The cell labeling rate and fluorescence intensity were analyzed. The other half of the cells was resuspended in RPMI 1640 medium for cell culture. The same steps were repeated after one and two days.

\section{In vivo fluorescence imaging}

For in vivo imaging, Ana- 1 cells $\left(1 \times 10^{6}\right.$ cells $)$ were initially labeled with $20 \mu \mathrm{g}$ FA-MEH-PPV- $\mathrm{NH}_{2}$ polymer dots for $12 \mathrm{~h}$.
After washing, the cells were resuspended in PBS. The labeled Ana-1 cells were subcutaneously injected at $2 \times 10^{6}$ cells per hind leg footpad (right) or in the caudal vein. In vivo fluorescence imaging was performed with the IVIS Lumina XRMS Series III Imaging System by using a $520 \mathrm{~nm}$ excitation filter and a $790 \mathrm{~nm}$ emission filter. In vivo fluorescence imaging was obtained under anesthesia and analyzed at $20 \mathrm{~min}, 80 \mathrm{~min}, 2 \mathrm{~h}$ and $2 \mathrm{~d}$ by using Living Image software.

Probe-based confocal laser endomicroscopy (pCLE) was conducted using the Cellvizio Dual Band System (Mauna Kea Technologies, Paris, France). In this study, a Z1800 scanning probe was used (diameter $=1.8 \mathrm{~mm}$, lateral resolution $=3.5$ $\mu \mathrm{m}$, working distance $=100 \mu \mathrm{m}$, max field of view $=600 \mu \mathrm{m}$, a

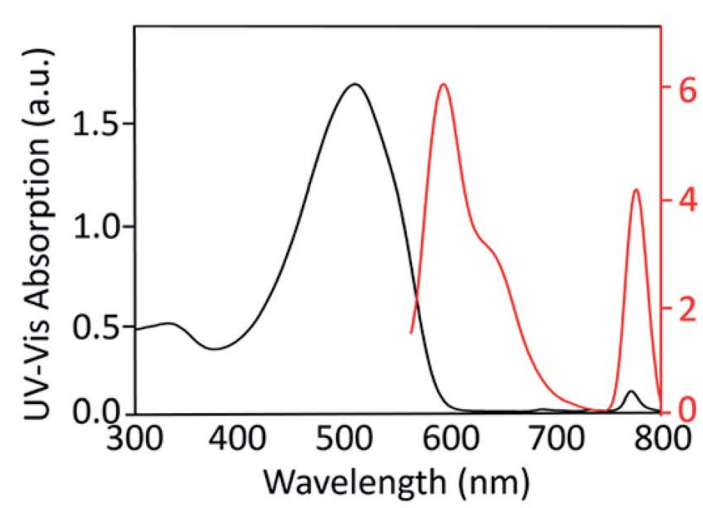

c

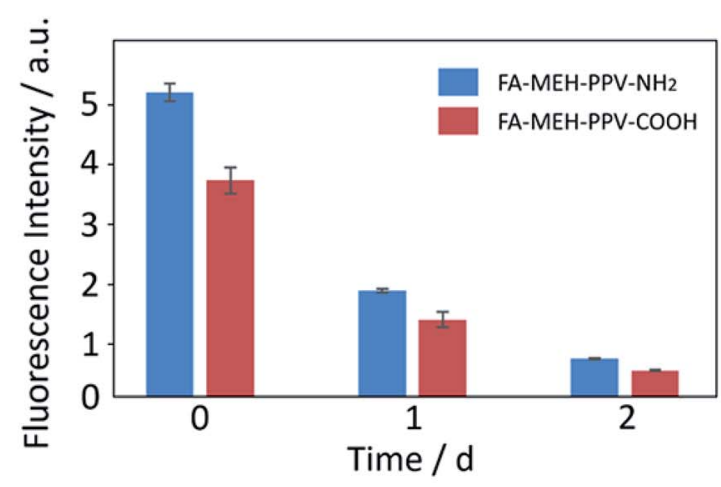

b

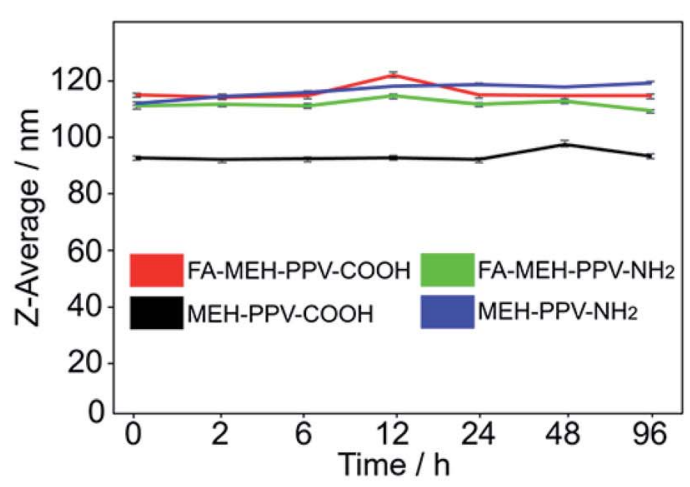

d

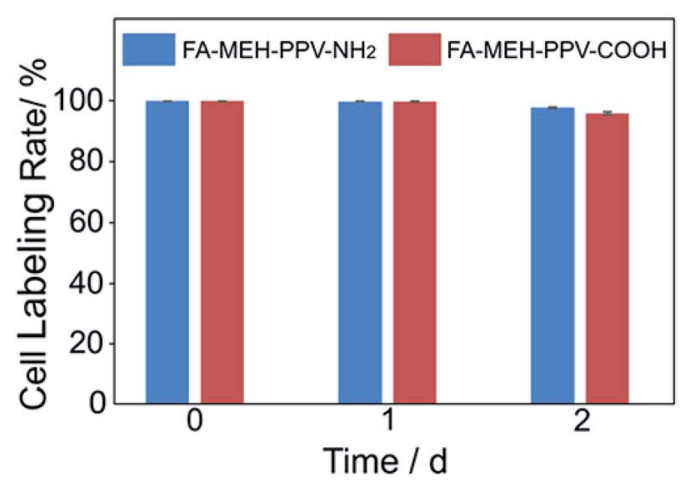

Fig. 1 Characterization of polymer dots. (a) UV/vis absorption and fluorescence spectra of the NIR polymer dots. The fluorescence spectra was obtained under $537 \mathrm{~nm}$ excitation, which showed the emission from the MEH-PPV and NIR 775; (b) Z-average of four different MEH-PPV polymer dots after treatment with DMEM containing 10\% FBS for 0, 2, 6, 12, 24, 48, 96 h, respectively; (c and d) cell labeling rate of FA-MEH-PPV$\mathrm{NH}_{2}$ and $\mathrm{MEH}-\mathrm{PPV}-\mathrm{NH}_{2}$ polymer dots in Ana-1 cells and fluorescence intensity for $0,1,2 \mathrm{~d}$ under serum-containing medium after labelled by MEH-PPV polymer dots. 
$\lambda_{\text {excitation }}=488 \mathrm{~nm}$ ), and the spectral detection $=505-700 \mathrm{~nm}$. Balb/c mice were anesthetized with $200 \mu \mathrm{L}$ of pentobarbital sodium (1\%) by intraperitoneal injection, and Ana-1 cells $(\sim 2000000)$ labeled with FA-MEH-PPV- $\mathrm{NH}_{2}$ polymer dots were injected via the tail vein or the right footpad. Polymer dots were excited at $488 \mathrm{~nm}$, and emission was collected from 505 to $700 \mathrm{~nm}$. The imaging and video of organs and lymph nodes were collected after $20 \mathrm{~min}, 120 \mathrm{~min}$ and $2 \mathrm{~d}$. The data were analyzed by matching software (IC viewer, Mauna Kea Technologies, Paris, France).
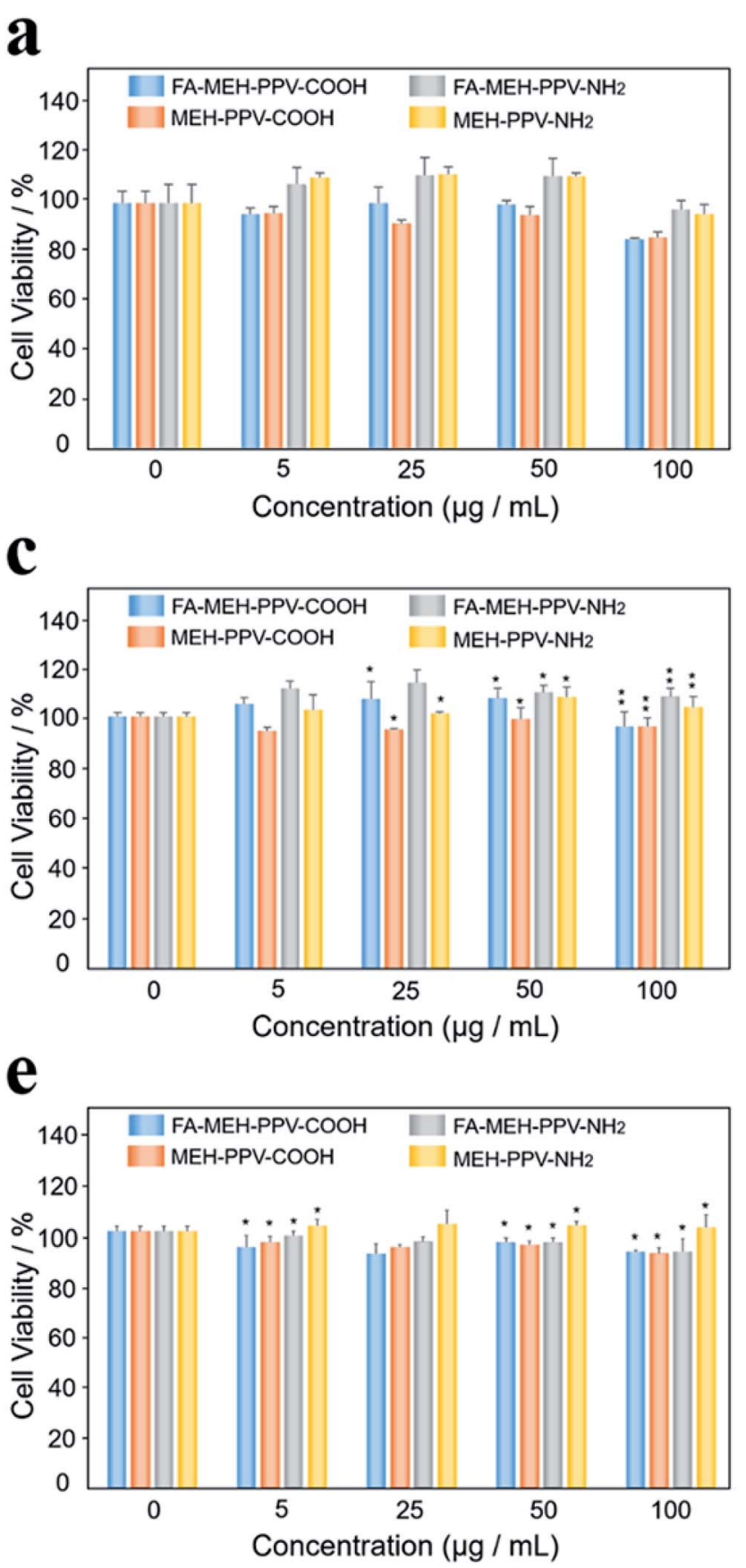

\section{Ex vivo imaging and analysis of the tissues}

After in vivo fluorescence imaging, the tissues were removed for ex vivo fluorescence imaging by using the IVIS Lumina XRMS Series III Imaging System by using a $520 \mathrm{~nm}$ excitation filter and a $790 \mathrm{~nm}$ emission filter. Then, the lymph nodes and organs were immediately fixed using $10 \%$ neutral buffered formalin and stored at $-80{ }^{\circ} \mathrm{C}$. Subsequently, the tissues were extracted and embedded in OCT compound and cryosectioned by microtome at $-20{ }^{\circ} \mathrm{C}$ into slices of $10 \mu \mathrm{m}$ thicknesses. The sections were analyzed under a fluorescence microscope. b

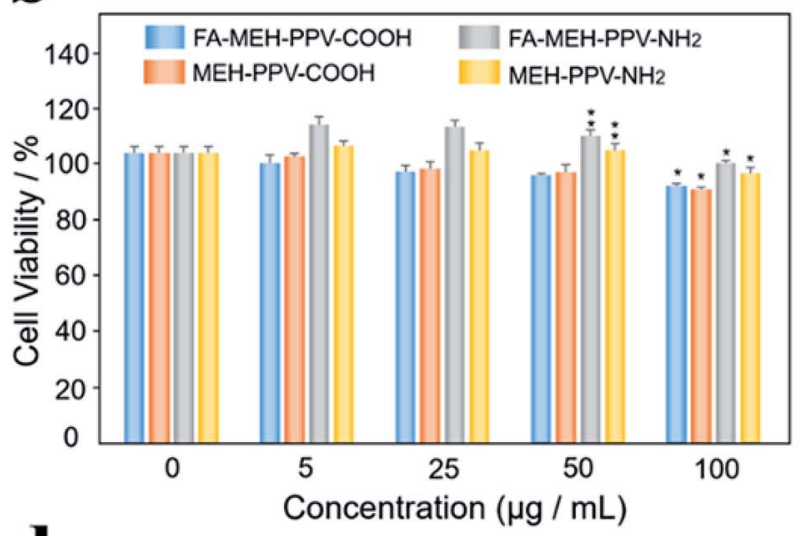

d

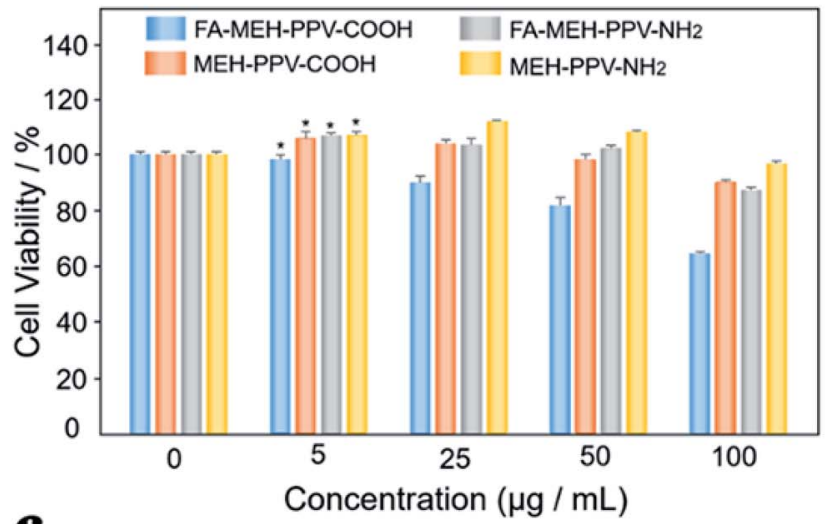

f

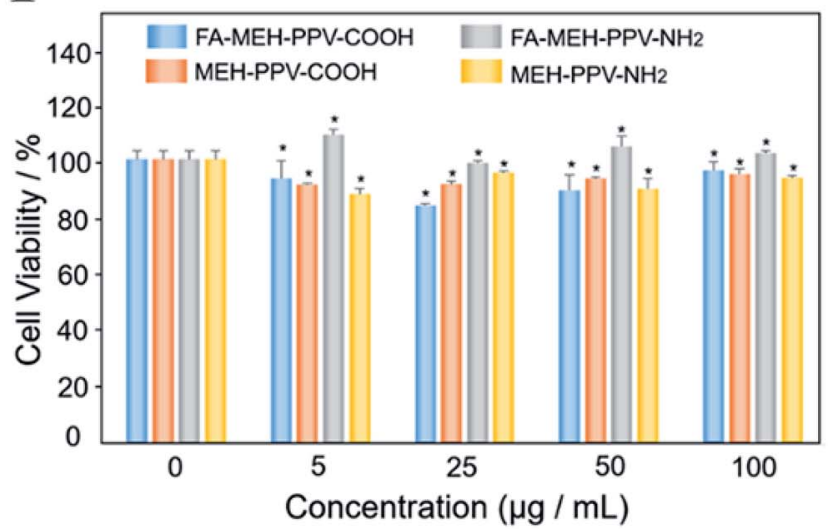

Fig. 2 Viability values (\%) of cells estimated by CCK- 8 assay of six cell lines treated with MEH-PPV polymer dots. Data represent mean \pm SD $(n=$ 5). (a) Ana-1, (b) H292, (c) QBC, (d) GBC-SD, (e) RBE, (f) SGC (*p $\leq 0.05$, **p $\leq 0.01$ ). 


\section{Results and discussion}

\section{Preparation and characterization of the polymer dots}

To discuss the influence of ligands on the cellular uptake in the Ana-1 cells, four typical MEH-PPV polymer dots were designed and prepared, including (1) MEH-PPV dots modified with folate and carboxyl (FA-MEH-PPV-COOH) had the hydrodynamic diameter of $50.38 \pm 5.43 \mathrm{~nm}$; (2) MEH-PPV dots modified with carboxyl (MEH-PPV-COOH) had the hydrodynamic diameter of $47.93 \pm 3.60 \mathrm{~nm}$; (3) MEH-PPV dots modified with folate and amino (FA-MEH-PPV-NH ${ }_{2}$ ) had the hydrodynamic diameter of $54.94 \pm 4.04 \mathrm{~nm}$; and (4) MEH-PPV dots modified with amino $\left(\mathrm{MEH}-\mathrm{PPV}-\mathrm{NH}_{2}\right)$ had the hydrodynamic diameter of $54.06 \pm$ $2.72 \mathrm{~nm}$. Table 1 and Scheme S1† describes the synthesis of these polymer dots. The high percentages of ligands improved the hydrophilicity and stability of the MEH-PPV polymer dots. The zeta potential of synthesized polymer dots was in the range of $-34.2 \mathrm{mV}$ to $-39.8 \mathrm{mV}$ in water. Due to the long negatively charged PMMA chain in MMA- $\mathrm{NH}_{2}$, the electropositive amino termination playing a negligible role, the particulate $\mathrm{MMA}-\mathrm{NH}_{2}$ having a negative zeta potential of $-23.8 \pm 3 \mathrm{mV} \cdot{ }^{45}$ And MMA$\mathrm{NH}_{2}$ modified FA-MEH-PPV-NH $\mathrm{N}_{2}$ and $\mathrm{MEH}-\mathrm{PPV}-\mathrm{NH}_{2}$ polymer dots also exhibited a negative zeta potential, which was consistent with our pervious results. ${ }^{42}$ The $\mathrm{pH}$ of the prepared polymer dots was between 6.38 and 6.60. And $Z$-average sizes versus $\mathrm{pH}$ change (Fig. S1†) illustrated good colloidal stability of the polymer dots.

The prepared polymer dots in water exhibited a broad peak at 505-510 $\mathrm{nm}$ and a weak NIR peak at $771 \mathrm{~nm}$. The absorption peaks represented the shift of MEH-PPV from $505 \mathrm{~nm}$ to $510 \mathrm{~nm}$ with increased diameters of the polymer dots. The redshift may be due to the fluorescence mechanism of conjugated polymer nanoparticles reported previously. ${ }^{46}$ The absorbance and fluorescence spectra of the prepared polymer dots were similar, and the spectra of FA-MEH-PPV- $\mathrm{NH}_{2}$ were shown in Fig. 1a. Under excitation at $537 \mathrm{~nm}$, the polymer dots exhibited emission at 595 and $778 \mathrm{~nm}$. And the conversion rate from MEH-PPV to NIR775 of the four typical polymer dots was in the range of $30-40 \%$. The FRET efficiency was defined by the ratio of the integrated total emission $(750-800 \mathrm{~nm})$ from the NIR775 to the integrated total emission $(562-750 \mathrm{~nm})$ from the MEH-PPV. ${ }^{47}$ Although the spectral overlap between MEH-PPV fluorescence and NIR775 absorbance was poor. ${ }^{48}$ The result showed an efficient fluorescence resonance energy transfer ratio, which displays bright fluorescence in the near-infrared region. The high fluorescence resonance energy transfer (FRET) exhibited a large Stokes shift between the excitation and emission, providing the possibility for the experiment in vivo. Furthermore, the fluorescence yield (QY) test reflected the high light-harvesting efficiency of polymer dots (Table S1 $\dagger$ ). The emission of MEH-PPV was above $12 \%$ and the emission of NIR775 was above $1 \%$. In addition, the physical stability of the MEH-PPV polymer dots was detected by dispersing these particles in DMEM supplemented with 10\% FBS and in different $\mathrm{pH}$. The $Z$-average size of these polymer dots showed no significant variation (Fig. $1 \mathrm{~b}$ and $\mathrm{S} 1 \dagger$ ), indicating their good colloidal stability.

\section{Cytotoxicity assay}

As shown in Fig. 2, different concentrations (0, 5, 25, 50, and 100 $\mu \mathrm{g} \mathrm{mL}^{-1}$ ) of the polymer dots were added to the Ana-1 cell line. After $24 \mathrm{~h}$ of incubation with the four kinds of polymer dots, the cells maintained greater than $85 \%, 85 \%, 97 \%$, and $95 \%$ cell viabilities for Ana-1 cells at $100 \mu \mathrm{g} \mathrm{mL}^{-1}$, respectively (Fig. 2a). At low concentrations, the cell viabilities showed a slight increase for the polymer dots modified with amino. Such as, the cellular

a

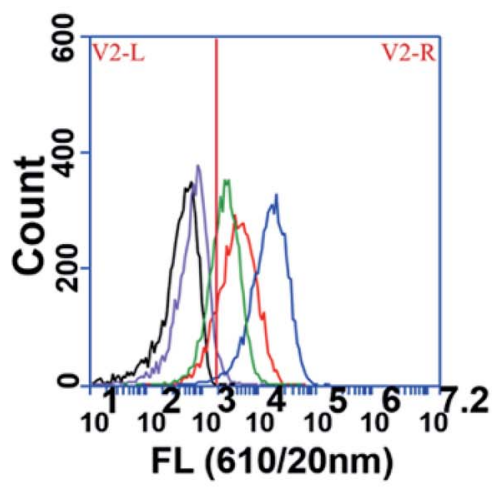

b
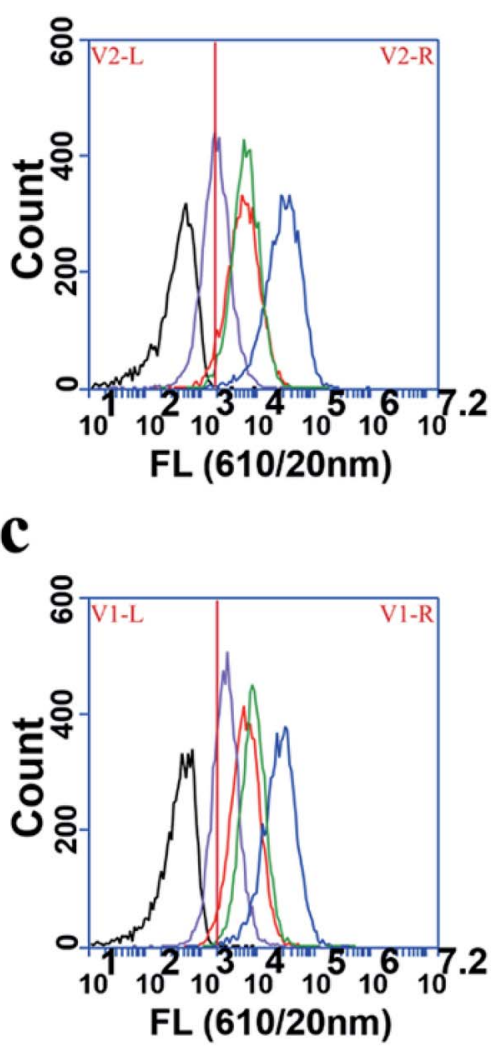

Fig. 3 Flow cytometry assay. Flow cytometric profiles of cellular uptake of four kinds of MEH-PPV polymer dots $(\sim 20 \mu \mathrm{g})$ in Ana-1 cells for 2, 6, $10 \mathrm{~h}$ under serum-containing medium. (a) $2 \mathrm{~h}$; (b) $6 \mathrm{~h}$; (c) $10 \mathrm{~h}$ (red: FA-MEH-PPV-COOH; purple: $\mathrm{MEH}-\mathrm{PPV}-\mathrm{COOH}$; blue: FA-MEHPPV-NH$H_{2}$; green: $F A-M E H-P P V-N_{2}$.) 
viability was estimated to be more than $110 \%$ for the Ana- 1 cell line at a concentration of $50 \mu \mathrm{g} \mathrm{mL}{ }^{-1}$, indicating the growth promoting effect of amino modified polymer dots on the cells at low concentrations. While for the polymer dots modified with carboxyl, the cellular viability decreased slowly with the sample concentration increased. Compared with the results reported by Eleonore Fröhlich, ${ }^{49}$ polymer dots with positive charge exhibited a higher cytotoxicity. While our results displayed the weak cytotoxicity of the prepared polymer dots under these conditions even for the polymer dots modified with MMA- $\mathrm{NH}_{2}$.

To further compare the cytotoxicity of polymer dots on different cells, five kinds of cancer cells were selected: lung cancer cell line NCI-H292, cholangiocarcinoma cell line QBC, gallbladder cancer cell line GBC-SD, SGC-996 cells and bile duct carcinoma cell line RBE. The viability was estimated to be higher than $90 \%$ for H292, QBC, SGC and RBE cell lines at 100 $\mu \mathrm{g} \mathrm{mL}^{-1}$, displaying that the prepared polymer dots showed minimal cytotoxicity within $24 \mathrm{~h}$ for these cancer cells. However, FA-MEH-PPV-COOH revealed low cytotoxicity at a concentration of $100 \mu \mathrm{g} \mathrm{mL}{ }^{-1}$ for the GBC-SD cell line (Fig. 2d), with the cell viability was $64 \%$. This result may be due to the special spindle morphology of GBC-SD cells, making cells sensitive to the environment, especially to the polymer dots modified by PE-FA and carboxyl. Besides, for the polymer dots modified with carboxyl, the viability of the tumor cells was slightly decreased with increasing concentration from 5 to $100 \mu \mathrm{g} \mathrm{mL} \mathrm{m}^{-1}$, but for QBC cells, the cellular viability showed an increase from 5 to 50 $\mu \mathrm{g} \mathrm{mL}^{-1}$ and decreased at $100 \mu \mathrm{g} \mathrm{mL}^{-1}$. For the polymer dots modified with amino, tumor cellular viability exhibited the same trend as macrophages.

\section{Biological distribution in balb/c mice}

To explore the biological distribution of MEH-PPV polymer dots in mice, the lymph nodes (cervical, axillary, inguinal, popliteal, and medial iliac lymph nodes), major organs (heart, liver, spleen, lungs, and kidneys), interscapular brown adipose tissue (iBAT), muscle and bone were removed and imaged. As shown in Fig. $\mathrm{S} 2, \dagger$ all the polymer dots exhibited high accumulation in the liver and spleen. While a few signals of $\mathrm{MEH}-\mathrm{PPV}-\mathrm{NH}_{2}$ polymer dots were observed in the lungs. Interestingly, the signals of $\mathrm{MEH}-\mathrm{PPV}-\mathrm{COOH}$ polymer dots were detected in the iBAT, cervical, axillary and medial iliac lymph nodes, indicating the long circulation time of polymer dots in the lymphatic vascular system.

\section{Flow cytometry assay and in vitro cell imaging}

To explore the cellular uptake rate of polymer dots in the Ana-1 cells, the flow cytometric profiles experiment was conducted. Polymer dots were incubated with Ana-1 cells in serumcontaining medium at 2, 6, and $10 \mathrm{~h}$ (Fig. 3). After $2 \mathrm{~h}$ incubation, as shown in Fig. 3a, FA-MEH-PPV-NH $\mathrm{N}_{2}$ polymer dots showed the highest cellular uptake of $98.94 \%$, followed by MEH-PPV- $\mathrm{NH}_{2}$ polymer dots with $75.88 \%$, and FA-MEH-PPV$\mathrm{COOH}$ polymer dots showed cellular uptake of $87.67 \%$. While MEH-PPV-COOH polymer dots showed lowest cellular uptake of $4.91 \%$. The results exhibited that Ana-1 cells are more likely to uptake polymer dots modified by amino in a short incubation time. As time increased to $6 \mathrm{~h}$, the cell labeling rate of polymer dots increased gradually. And MEH-PPV-COOH polymer dots showed a rapid increase in the cellular uptake from $4.91 \%$ to $53.20 \%$.

After $10 \mathrm{~h}$ incubation, the labeling rate of FA-MEH-PPV- $\mathrm{NH}_{2}$ and $\mathrm{MEH}-\mathrm{PPV}-\mathrm{NH}_{2}$ polymer dots was over $98 \%$, and the FAMEH-PPV-COOH exhibited cell labeling rate over $81 \%$, while the labeling rate of MEH-PPV-COOH polymer dots was only $57.17 \%$. This experiment showed that Ana-1 cells were likely to absorb polymer dots with surface modification of amino and folate ligands. Our results were not consistent with the report of $\mathbf{a}$

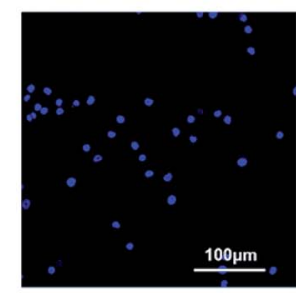

b

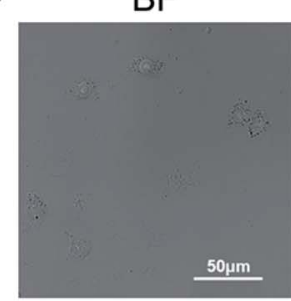

MEH-PPV

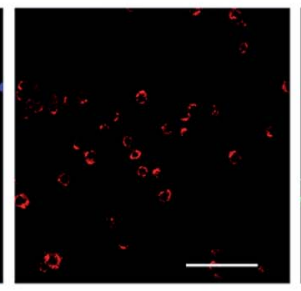

DAPI

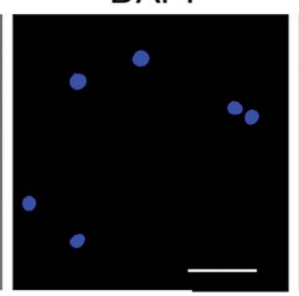

NIR775

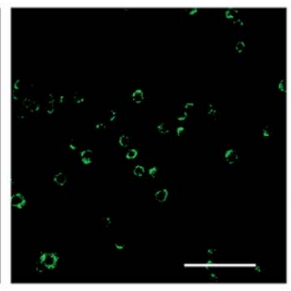

$\mathrm{F} 4 / 80$

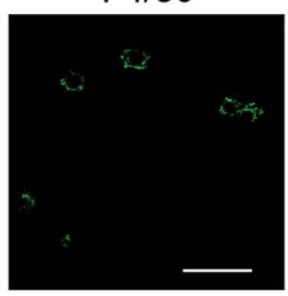

Overlay

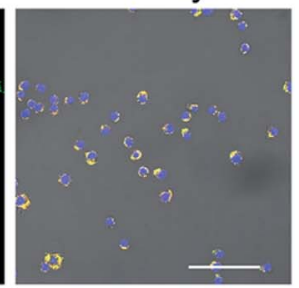

Overlay

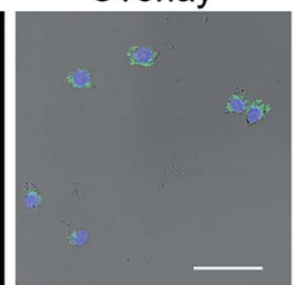

Fig. 4 Immunofluorescence and fluorescence imaging of Ana-1 cells. (a) Fluorescence imaging of Ana-1 cells incubated with FA-MEH-PPV-NH 2 polymer dots $(\sim 20 \mu \mathrm{g})$ under serum-containing medium for $24 \mathrm{~h}$. Ana-1 cells costained with DAPI (blue, excitation: $405 \mathrm{~nm}$, emission: $430-520 \mathrm{~nm}$ ). MEH-PPV (red, excitation: $561 \mathrm{~nm}$, emission: 585-650 nm), NIR775 (green, excitation: $561 \mathrm{~nm}$, emission: 750-790 nm); (b) immunofluorescence staining. Ana-1 cells costained with DAPI (blue, excitation: 405 nm, emission: 430-520 nm), F4/80 (green, excitation: 488 nm, emission: $508-530$ nm). 
the uptake of $\mathrm{NH}_{2}$ (PEG) QDs. ${ }^{50}$ It may due to the structure of MMA- $\mathrm{NH}_{2}$ used in this work and the different cell lines or different uptake mechanism. ${ }^{51}$

The cellular uptake and location of polymer dots were further studied by cell imaging. The emission was collected from $620-710 \mathrm{~nm}$ with excitation at $546 \mathrm{~nm}$, and the cells were incubated with four typical MEH-PPV polymer dots for 2, 6, and $10 \mathrm{~h}$ (Fig. S3 and S4 $\dagger$ ). The signals were detected uniformly in the cytoplasm. In particular, FA-MEH-PPV-NH $\mathrm{N}_{2}$ polymer dots exhibited strong fluorescence in the cells under the microscope and the cell labeling rate was above $97 \%$ in $2 \mathrm{~h}$. In contrast, $\mathrm{MEH}-\mathrm{PPV}-\mathrm{COOH}$ polymer dots showed much less fluorescence in the cells. Moreover, both the fluorescence intensity and cellular uptake rate increased over time. The results of cell imaging were consistent with the flow cytometry analysis, suggesting that FA-MEH-PPV-NH $\mathrm{NH}_{2}$ showed highest cellular uptake among the prepared polymer dots.

Laser confocal imaging was used to further study the location of polymer dots in the Ana-1 cells. As shown in Fig. 4a, the cells are evenly distributed and in a good state. FA-MEH-PPV$\mathrm{NH}_{2}$ polymer dots exhibited strong fluorescence in both the visible and near-infrared regions. The signals were distributed mainly in the cytoplasm around the nucleus. The MEH-PPV and NIR775 channels displayed an efficient FRET ratio. The high FRET efficiency and strong NIR fluorescence indicated that the FA-MEH-PPV-NH $\mathrm{NH}_{2}$ polymer dots were suitable for in vivo study.

To analyze the specific protein markers F4/80 of macrophages, Ana-1 cells were investigated by immunofluorescence staining and laser confocal imaging. As shown in Fig. $4 \mathrm{~b}$, the macrophage surface antigen $\mathrm{F} 4 / 80$ emission was obtained from 508 to $530 \mathrm{~nm}$ with excitation at $488 \mathrm{~nm}$. The cell nuclei were regularly distributed in the center of the cell, and the specific protein F4/80 was evenly distributed on the surface of the cell membrane. The positive result of immunofluorescence staining indicated that Ana- 1 cells are a type of phagocyte.

To explore the long-term labeling rate and fluorescence stability of polymer dots, the labeled Ana-1 cells were incubated for 2 d. As shown in Fig. 1c, the fluorescence intensity of Ana-1 cells labeled with FA-MEH-PPV-NH $\mathrm{NH}_{2}$ decreased to $35 \%$ after 1 $\mathrm{d}$ and to $13 \%$ after $2 \mathrm{~d}$, and the fluorescence intensity of Ana-1 cells labeled with FA-MEH-PPV-COOH decreased to $36 \%$ after 1 $\mathrm{d}$ and to $13 \%$ after $2 \mathrm{~d}$. The cell labeling rate of these polymer dots in Ana-1 cells was still over 95\% at $2 \mathrm{~d}$ (Fig. 1d), providing the basis for the in vivo cell tracking experiment.
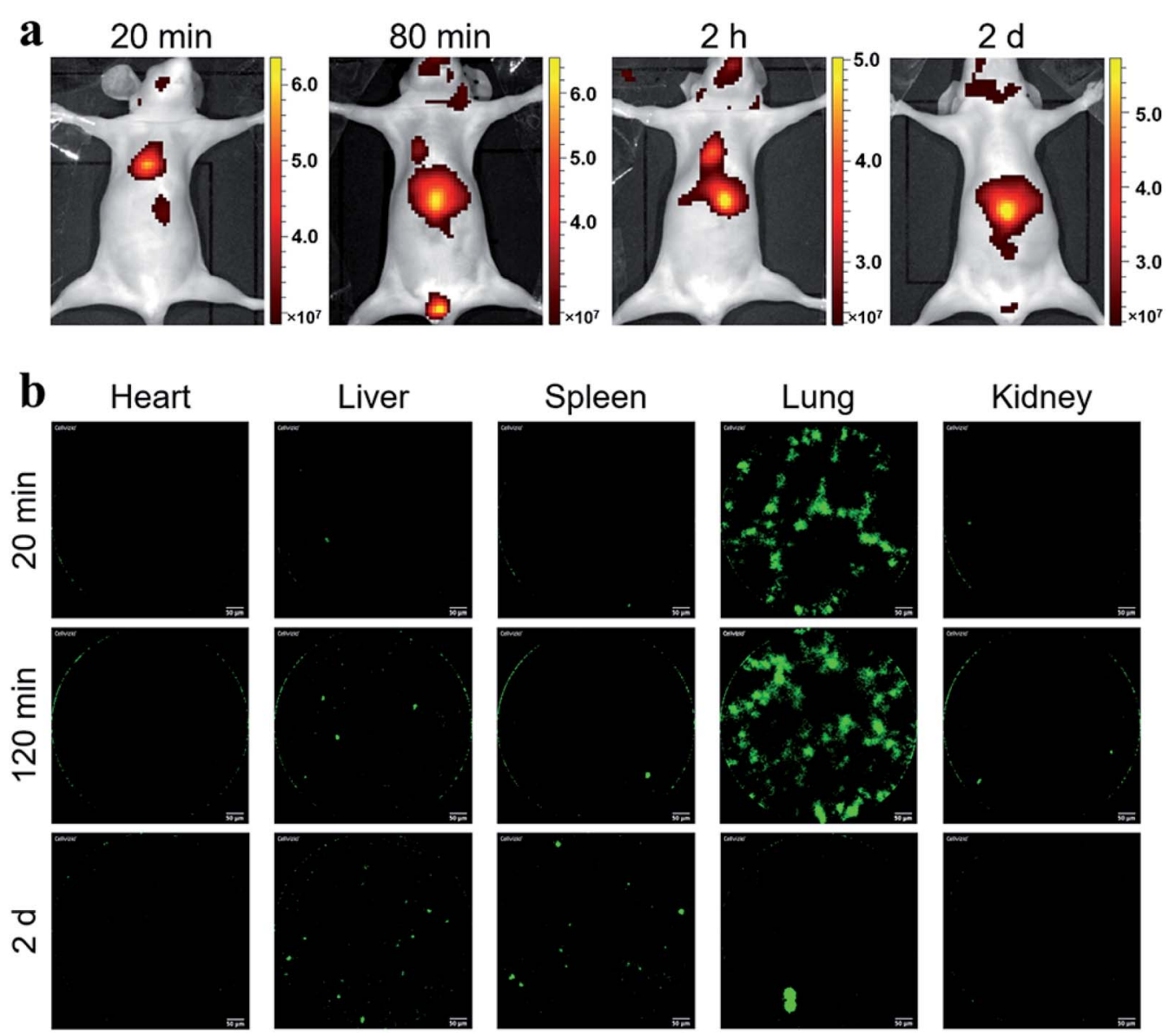

Fig. 5 (a) In vivo fluorescence imaging of mice $(n=3)$ for $20,80,120$ min and 2 d after intravenous injection of Ana- 1 cells ( $~ 5000000)$ labeled by FA-MEH-PPV-NH $\mathrm{NH}_{2}$ polymer dots, respectively (excitation filter, $520 \pm 15 \mathrm{~nm}$; emission filter, $790 \pm 10 \mathrm{~nm}$ ); (b) real-time in vivo cell tracking. Imaging of the fluorescence signals in heart, liver, spleen, lung and kidney at $20 \mathrm{~min}, 120 \mathrm{~min}$, and $2 \mathrm{~d}$ post injection, respectively (excitation = $488 \mathrm{~nm}$ and the spectral detection $=505-700 \mathrm{~nm}$ ). 


\section{In vivo NIR fluorescence imaging}

Considering the fluorescence intensity and high cell labeling rate, the FA-MEH-PPV- $\mathrm{NH}_{2}$ polymer dots were used in in vivo experiments. To explore the cell migration in blood circulation and signal distribution in organs, Ana-1 cells labeled by FA-MEH-PPV-NH $\mathrm{H}_{2}$ polymer dots were injected into the caudal vein of mice. NIR fluorescence imaging was carried out at $20 \mathrm{~min}, 80 \mathrm{~min}, 120 \mathrm{~min}$ and $2 \mathrm{~d}$ post injection (Fig. 5a). At $20 \mathrm{~min}$, intense NIR signals in the lung were observed with weak signals in the liver and face. At 80 and $120 \mathrm{~min}$, the NIR signals in the liver became intense. And NIR signals in the neck region and urinary bladder were visualized. The signals in the bladder were produced by the autofluorescence of the mice. ${ }^{52}$ At $2 \mathrm{~d}$, intense NIR signals in the liver were observed, while no obvious signals in the lungs were visualized. From $20 \mathrm{~min}$ to $2 \mathrm{~d}$, the signals gradually migrated from the lungs to the liver. The results were similar to those reported for other cell lines. ${ }^{43,53}$ In addition, organs were dissected at $20 \mathrm{~min}$ and $2 \mathrm{~h}$ post injection. As shown in Fig. S5a and $\mathrm{b}, \uparrow$ ex vivo imaging revealed that the ingestion of probes increased in the spleen and liver. While the region-of-interest measurements showed that the fluorescence intensity in the lung decreased to $50 \%$ from $20 \mathrm{~min}$ to $2 \mathrm{~h}$. Furthermore, frozen sections of the organs demonstrated that strong signals were visualized in the edge of the alveolus of lung as well as in the spleen and liver (Fig. S6†). These results were consistent with the in vivo imaging results, suggesting the migration of labelled Ana-1 cells in the deep organs and the endothelial reticular system.

To further explore the cell migration in lymphatic system, the labeled Ana-1 cells were injected into the right footpads of mice. As shown in Fig. 6a, most fluorescent signals were still concentrated on the footpad after $2 \mathrm{~d},{ }^{54}$ and no obvious signals were detected in the draining lymph nodes. Therefore, the bilateral inguinal, sciatic, and popliteal lymph nodes were isolated, and ex vivo imaging confirmed that fluorescence signal was detected in the popliteal lymph node at the experimental side (Fig. S5c $\dagger$ ), indicating that the migration of labelled Ana-1 cells in the lymphatic system.

\section{In vivo real-time pCLE}

Probe-based confocal laser endomicroscopy (pCLE) was further used to demonstrate the distribution of labeled Ana-1 cells in mice. As shown in Fig. 5b, after the intravenous injection of Ana-1 cells labeled with FA-MEH-PPV- $\mathrm{NH}_{2}$ for $20 \mathrm{~min}$, intense signals were visualized in the lungs with weak signals in the heart, liver, spleen and kidney. As shown in the ESI movie S1, $\uparrow$ the signals of Ana-1 cells were round with clear boundaries between cells. Notably, the signals of cells in the alveolus of lung were observed, and there were more than three alveolus were simultaneously visualized in the field of vision with high signal-noise-ratio. After $2 \mathrm{~h}$, the most signals were still observed in the lungs (ESI movie S2 $\dagger$ ), and with a slight increase in the liver. After $2 \mathrm{~d}$, the signal in the lungs decreased while the signal increased in the liver and spleen. From $20 \mathrm{~min}$ to $2 \mathrm{~d}$, the signals gradually migrated from the lungs to the liver. The pCLE provided realtime high resolution visualizing labelled cells in the alveolus of lung, this result was consistent with in vivo NIR imaging. Besides, because the in vivo fluorescence imaging involves the superposition of two-dimensional images, providing the fluorescence signal of the whole tissue, while the pCLE provided the signals at the focal plane of the ROI (region of interest). Therefore, the fluorescence signals in the liver were much higher detected by in vivo fluorescence imaging than that detected by pCLE.

As shown in Fig. 6b, after 2 d intradermal injection of Ana-1 cells labeled with FA-MEH-PPV- $\mathrm{NH}_{2}$ at the footpad of mice, massive signals were visualized in the popliteal lymph node, and scattered signals were also observed in the inguinal lymph node. This result indicated that the phagocytes can reach the popliteal and inguinal lymph node from the injection site. Compared with in vivo fluorescence imaging, pCLE displayed higher sensitivity to detect the migration of labelled cells in the draining lymph nodes.
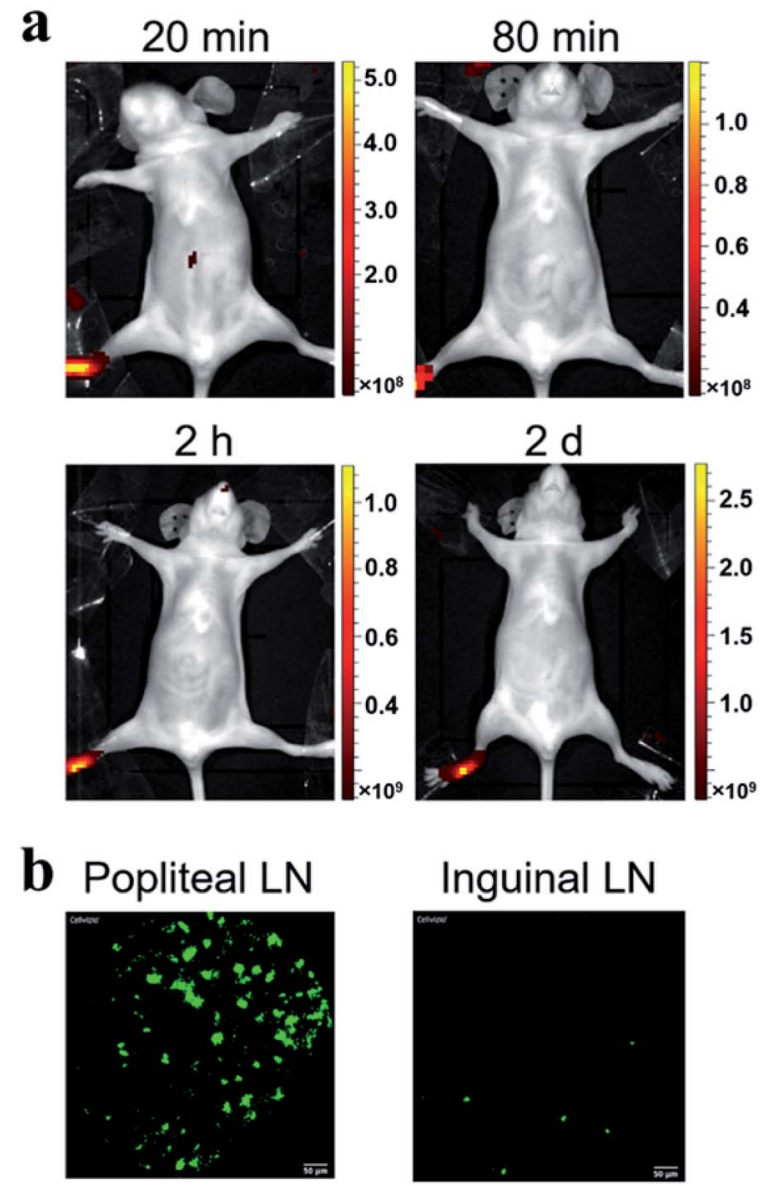

Fig. 6 (a) In vivo fluorescence imaging of mice $(n=3)$ for 20,80 , $120 \mathrm{~min}$ and $2 \mathrm{~d}$ after footpad injection of Ana-1 cells ( 5000000$)$ labeled by $\mathrm{FA}-\mathrm{MEH}-\mathrm{PPV}-\mathrm{NH}_{2}$ polymer dots, respectively (excitation filter, $520 \pm 15 \mathrm{~nm}$; emission filter, $790 \pm 10 \mathrm{~nm}$ ). (b) Real-time in vivo cell tracking. Signals in popliteal and inguinal lymph nodes for $2 \mathrm{~d}$ after footpad injection (excitation $=488 \mathrm{~nm}$ and the spectral detection $=$ 505-700 nm). 


\section{Conclusions}

In summary, we designed and compared four typical polymer dots with different ligands for tracking macrophage cells. The in vitro cytotoxicity experiment demonstrated low cytotoxicity of the synthesized polymer dots in the macrophage Ana- 1 cells and tumor cells. Moreover, flow cytometry and cell imaging analysis showed that both folate and amino modification increased uptake of polymer dots in the Ana-1 cells. In addition, the in vivo NIR fluorescence imaging demonstrated that labeled Ana-1 cells showed strong and rapid uptake in the lungs of mice. Furthermore, the real-time high-resolution imaging of labelled Ana- 1 cells in the alveolus of lung and lymph nodes were recorded by pCLE. This result provides a new strategy for combination polymer dots and pCLE for in vivo high resolution tracking the fate of macrophage cells in organs.

\section{Live subject statement}

All animal procedures were performed in accordance with the Guidelines for Care and Use of Laboratory Animals of Shanghai Jiao Tong University and experiments were approved by the Animal Ethics Committee of Shanghai Jiao Tong University (Shanghai, China).

\section{Conflicts of interest}

There are no conflicts to declare.

\section{Acknowledgements}

This study was supported by grants from the National Key R\&D Program of China (2016YFC1303100), the National Natural Science Foundation of China (81671738, 81301261, and 21374059), the Shanghai Pujiang Project (13PJ1405000), and the Medicine-Engineering Cross Project of Shanghai Jiao Tong University (YG2015MS67).

\section{Notes and references}

1 D. M. Kurtz and S. S. Gambhir, Adv. Cancer Res., 2014, 124, 257-296.

2 J. Galon, Science, 2006, 313, 1960-1964.

3 S. Anguille, E. L. Smits, E. Lion, V. F. Van Tendeloo and Z. N. Berneman, Lancet Oncol., 2014, 15, 257-267.

4 T. J. Curiel, G. Coukos, L. Zou, X. Alvarez, P. Cheng, P. Mottram, M. Evdemon-Hogan, J. R. Conejo-Garcia, L. Zhang and M. Burow, Nat. Med., 2004, 10, 942-949.

5 R. Medzhitov, Nature, 2008, 454, 428-435.

6 C. N. Serhan and J. Savill, Nat. Immunol., 2005, 6, 1191.

7 A. L. Doedens, C. Stockmann, M. P. Rubinstein, D. Liao, N. Zhang, D. G. DeNardo, L. M. Coussens, M. Karin, A. W. Goldrath and R. S. Johnson, Cancer Res., 2010, 70, 7465-7475.

8 B. Z. Qian and J. W. Pollard, Cell, 2010, 141, 39-51.

9 R. Weissleder, M. Nahrendorf and M. J. Pittet, Nat. Mater., 2014, 13, 125-138.
10 C. N. Lumeng and A. R. Saltiel, J. Clin. Invest., 2011, 121, 2111-2117.

11 I. Tabas, Nat. Rev. Immunol., 2010, 10, 36-46.

12 B. Ruffell, N. I. Affara and L. M. Coussens, Trends Immunol., 2012, 33, 119-126.

13 A. P. Anselmo, S. Pilotti and A. Mantovani, Cancer Cell, 2013, 23, 249-262.

14 J. Choi, H. Y. Kim, E. J. Ju, J. Jung, J. Park, H. K. Chung, J. S. Lee, J. S. Lee, H. J. Park and S. Y. Song, Biomaterials, 2012, 33, 4195-4203.

15 S. K. Patel and J. M. Janjic, Theranostics, 2015, 5, 150-172.

16 S. Kim, C. K. Lim, J. Na, Y. D. Lee, K. Kim, K. Choi, J. F. Leary and I. C. Kwon, Chem. Commun., 2010, 46, 1617.

17 C. Zhu, L. Liu, Q. Yang, F. Lv and S. Wang, Chem. Rev., 2012, 112, 4687-4735.

18 K. Li and B. Liu, Chem. Soc. Rev., 2014, 43, 6570.

19 C. Wu, B. Bull, C. Szymanski, K. Christensen and J. McNeill, ACS Nano, 2008, 2, 2415-2423.

20 J. V. Frangioni, Curr. Opin. Chem. Biol., 2003, 7, 626-634.

21 V. Ntziachristos, C. Bremer and R. Weissleder, Eur. Radiol., 2003, 13, 195-208.

22 J. C. Rasmussen, I. C. Tan, M. V. Marshall, C. E. Fife and E. M. Sevick-Muraca, Curr. Opin. Biotechnol., 2009, 20, 74-82.

23 A. Wagh, S. Y. Qian and B. Law, Bioconjug. Chem., 2012, 23, 981-992.

24 T. Kitai, T. Inomoto, M. Miwa and T. Shikayama, Breast Cancer, 2005, 12, 211-215.

25 N. Unno, M. Nishiyama, M. Suzuki, N. Yamamoto, K. Inuzuka, D. Sagara, H. Tanaka and H. Konno, Eur. J. Vasc. Endovasc. Surg., 2008, 36, 230-236.

26 J. Pecher and S. Mecking, Chem. Rev., 2010, 110, 6260-6279. 27 Y. Jiang, P. K. Upputuri, C. Xie, Y. Lyu, L. Zhang, Q. Xiong, M. Pramanik and K. Pu, Nano Lett., 2017, 17, 4964-4969.

28 S. Santra and A. Malhotra, Wiley Interdiscip. Rev.: Nanomed. Nanobiotechnol., 2011, 3, 501-510.

29 C. Wu and D. T. Chiu, ChemInform, 2013, 52, 3086-3109.

30 Y. Jin, F. Ye, M. Zeigler, C. Wu and D. T. Chiu, ACS Nano, 2011, 5, 1468.

31 Y. Lyu and K. Pu, Adv. Sci., 2017, 4, 1600481.

32 Y. Lyu, J. Zeng, Y. Jiang and K. Pu, ACS Nano, 2018, 12, 18011810.

33 C. Xie, X. Zhen, Q. Miao and K. Pu, Adv. Mater., 2018, 30, 1801331.

34 Q. Miao, C. Xie, X. Zhen and K. Pu, Nat. Biotechnol., 2017, 35, 1102-1110.

$35 \mathrm{X} . \mathrm{Xu}, \mathrm{R}$. Liu and L. Li, Chem. Commun., 2015, 51, 1673316749.

36 F. Tang, C. Wang and L. Li, ACS Appl. Mater. Interfaces, 2015, 7, 25077-25083.

37 Y. Lv, M. Liu and Z. Tian, ACS Nano, 2018, 12, 1350-1358.

38 S. Chen, S. Cui and Y. Zhang, J. Mater. Chem. B, 2018, 6, 7871-7876.

39 F. Cao and L. Xiong, Chin. J. Chem., 2016, 34, 570-575.

40 L. Xiong, A. J. Shuhendler and J. Rao, Nat. Commun., 2012, 3, 1193.

41 F. Cao, Y. Guo, Y. Li, S. Tang, Y. Yang, H. Yang and L. Xiong, Adv. Funct. Mater., 2018, 1707174. 
42 Y. Guo, Y. Li and Y. Yang, ACS Appl. Mater. Interfaces, 2018, 10, 20884.

43 L. Xiong, F. Cao, X. Cao, Y. Guo, Y. Zhang and X. Cai, Bioconjug. Chem., 2015, 26, 817-821.

44 J. Qin, Z. Peng and B. Li, Nanoscale, 2015, 7, 13991-14001.

45 M. Khademi, W. M. Wang and W. Reitinger, Langmuir, 2017, 33, 10473-10482.

46 R. Potai and R. Traiphol, J. Colloid Interface Sci., 2013, 403, 58-66.

47 M. K. So, A. M. Loening and S. S. Gambhir, Nat. Protoc., 2006, 1, 1160-1164.

48 D. Chen, Q. Li, Z. Meng, L. Guo, Y. Tang, Z. Liu, S. Yin, W. Qin, Z. Yuan and X. Zhang, Theranostics, 2017, 7, 18201834.
49 F. Eleonore, Int. J. Nanomed., 2012, 7, 5577-5591.

50 M. J. D. Clift, B. Rothen-Rutishauser and D. M. Brown, Toxicol. Appl. Pharmacol., 2008, 232, 418-427.

51 O. Lunov, T. Syrovets and C. Loos, ACS Nano, 2011, 5, 16571669.

52 M. C. Jacobson, R. D. White and S. G. Demos, J. Biomed. Opt., 2012, 17, 036011.

53 Z. Zhang, Y. Yuan, Z. Liu, H. Chen, D. Chen, X. Fang, J. Zheng, W. Qin and C. Wu, ACS Appl. Mater. Interfaces, 2018, 10, 26928.

54 N. L. Trevaskis, L. M. Kaminskas and C. J. H. Porter, Nat. Rev. Drug Discovery, 2015, 14, 781. 